THU0294

TREATMENT PATTERNS, DISEASE BURDEN AND OUTCOMES IN PATIENTS WITH GIANT CELL ARTERITIS AND POLYMYALGIA RHEUMATICA

Gary Craig ${ }^{1,2}$, Keith Knapp ${ }^{2}$, Bob Salim ${ }^{3}$, Shalini Mohan ${ }^{4}$, Margaret Michalska ${ }^{5}$. ${ }^{1}$ Arthritis Northwest, Spokane, United States of America; ${ }^{2}$ Discus Analytics, Spokane, United States of America; ${ }^{3}$ Axio Research, Seattle, United States of America; ${ }^{4}$ Genentech, Inc., South San Francisco, United States of America; ${ }^{5}$ Genentech, Inc, South San Francisco, United States of America

Background: For patients with giant cell arteritis (GCA) and/or polymyalgia rheumatica (PMR), glucocorticoids are the mainstay of treatment. However, due to the chronic nature of these diseases, patients may require continued glucocorticoid treatment to achieve treatment targets or prevent disease relapse, over time resulting in high cumulative doses and associated adverse events.

Objectives: To assess patterns of glucocorticoid use and outcomes in patients with GCA, PMR or both.

Methods: This retrospective cohort study used electronic medical records from a single US community-based rheumatology clinic utilizing the JointMan rheumatology software application. Patients age $\geq 50$ years with a diagnosis of either GCA or PMR and $\geq 1$ entry for glucocorticoid following the diagnosis were included and followed until lost to follow-up or the end of the study period (30 Nov 2017). The index date was defined as the date of first glucocorticoid prescription received at or after the earliest GCA or PMR diagnosis date. Outcomes at 2 years included the proportion of patients achieving remission (defined as not receiving steroids for $\geq 6$ months), time to remission, persistence of remission (defined as not receiving steroids for $\geq 6$ months and still not receiving steroids at 2 years) and prednisone dose at follow-up, and were compared between patients with GCA only, PMR only or both GCA and PMR. $P$ values are reported using $F$-test (ANOVA) for continuous variables and Chi-squared test for categorical variables.

Results: We identified 81 patients with GCA only, 779 with PMR only and 97 with GCA and PMR. Mean (SD) age was 70.0 (9.1) years; $64.2 \%$ were women. Mean (SD) daily prednisone dose at the index date was 46.7 (30.9) $\mathrm{mg}$ for patients with GCA only, 20.1 (14.2) for PMR only and 29.0 (23.4) for patients with both GCA and PMR. Two years after the index date, $32 \%$ of patients with GCA only, 32\% with PMR only and $27 \%$ with GCA and PMR had achieved remission; $17 \%, 23 \%$ and $18 \%$ were in persistent remission, respectively (Table 1), with no significant differences between groups. Among patients who achieved remission, overall median time to first remission was 202.5 (0-635) days and was shorter for patients with both GCA and PMR (157 [0-619] days) vs GCA (213 [0-577] days) or PMR (203.5 [0-635] days) only. KaplanMeier estimates of time to remission for each group are shown (Figure 1. ). Most patients required a daily prednisone dose at 2 years, with similar doses observed between groups (Table 2).

Conclusion: Patients with either GCA and/or PMR are exposed to significant doses of prednisone. In this study, fewer than one-third of patients with GCA and/or PMR achieved remission; the majority of patients continued to require prednisone therapy for at least 2 years after its initiation. These data highlight the need for the use of more efficacious and steroid-sparing therapies in patients with GCA and/or PMR.

\begin{tabular}{|c|c|c|c|c|c|}
\hline Total patients & $\begin{array}{l}\text { GCA Only } \\
(\mathrm{N}=81)\end{array}$ & $\begin{array}{l}\text { PMR Only } \\
(\mathrm{N}=779)\end{array}$ & $\begin{array}{l}\text { GCA and } \\
\text { PMR } \\
(\mathrm{N}=97)\end{array}$ & $\begin{array}{c}\text { Total } \\
(\mathrm{N}=957)\end{array}$ & $\begin{array}{c}P \\
\text { Value }\end{array}$ \\
\hline $\begin{array}{l}\text { Achieved remission, } \mathbf{n} \\
(\%)\end{array}$ & $26(32.1)$ & $248(31.8)$ & $26(26.8)$ & $300(31.3)$ & 0.7921 \\
\hline $\begin{array}{l}\text { Persistent remission, } \mathbf{n} \\
(\%)\end{array}$ & $14(17.3)$ & $176(22.6)$ & $17(17.5)$ & $207(21.6)$ & 0.5139 \\
\hline \multicolumn{6}{|l|}{ Time to remission, days ${ }^{\star}$} \\
\hline Mean (SD) & $\begin{array}{c}224.3 \\
(171.7)\end{array}$ & $\begin{array}{c}226.5 \\
(198.6)\end{array}$ & $208.4(186.6)$ & $\begin{array}{c}224.7 \\
(194.9)\end{array}$ & 0.0361 \\
\hline Median (range) & $213(0-577)$ & $\begin{array}{c}203.5(0- \\
635)\end{array}$ & $157(0-619)$ & $\begin{array}{c}202.5(0- \\
635)\end{array}$ & \\
\hline
\end{tabular}

* Among patients who achieved remission.

Abstract THU294 - Table 2. Prednisone Dose at 2 Years Post-Index Date

\begin{tabular}{lccccc}
\hline & $\begin{array}{c}\text { GCA Only } \\
(\mathbf{N}=\mathbf{2 6})\end{array}$ & $\begin{array}{c}\text { PMR Only } \\
(\mathbf{N}=\mathbf{3 4 1})\end{array}$ & $\begin{array}{c}\text { GCA and PMR } \\
\mathbf{( N = 6 0 )}\end{array}$ & $\begin{array}{c}\text { Total } \\
(\mathbf{N}=\mathbf{4 2 7})\end{array}$ & $\boldsymbol{P}$ Value \\
\hline $\begin{array}{l}\text { Prednisone dose, } \mathbf{m g} / \text { day }^{*} \\
\text { Mean (SD) }\end{array}$ & $9.5(10.6)$ & $8.8(9.2)$ & $12.6(15.9)$ & $9.4(10.5)$ & 0.0819 \\
Median (range) & $5(0-40)$ & $5(0-66)$ & $7.5(0-80)$ & $5(0-80)$ & \\
\hline
\end{tabular}

* Among patients who had prednisone dose information available at 2 years.
Figure 1. Time to Remission Following Initiation of Glucocorticoids

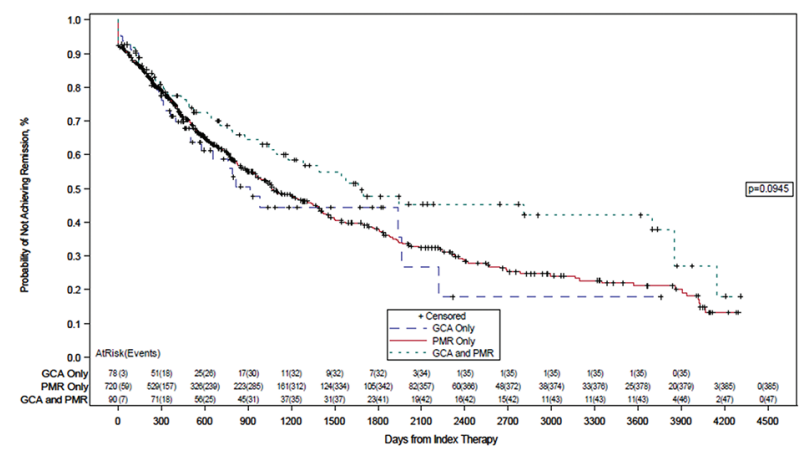

Abstract THU0294 - Figure 1

Disclosure of Interests: Gary Craig Shareholder of: co-owner of Arthritis NW, PLLC and Discus Analytics, LLC, Consultant for: advisory board for Premera Blue Cross, Speakers bureau: Bristol-Myers Squibb, Eli Lilly, Genentech, Celgene, AbbVie, Novartis, and Sandoz, Keith Knapp Employee of: Discus Analytics, Bob Salim Employee of: Axio Research, Shalini Mohan Shareholder of: Genentech, Inc., Employee of: Genentech, Inc, Margaret Michalska Employee of: Genentech, Inc.

DOI: 10.1136/annrheumdis-2019-eular.551

\section{THU0295 POLYMYALGIA RHEUMATICA ASSOCIATED WITH GIANT CELL ARTERITIS CONFIGURES A SUBTYPE WITH LOWER MORTALITY WITHIN GIANT CELL ARTERITIS}

Carmen de Frutos Fernández ${ }^{1}$, Maria Angeles Martinez Huedo ${ }^{2}$, Irene Monjo ${ }^{3}$, Eugenio de Miguel ${ }^{3} .{ }^{1}$ Medicine Student Universidad Autónoma de Madrid.

Rheumatology service, Hospital Universitario la Paz-IdiPaz., Madrid, Spain; ${ }^{2} U$. Docencia e Investigación. Hospital Universitario La Paz. Madrid, Madrid, Spain;

${ }^{3}$ Rheumatology service, Hospital Universitario la Paz-IdiPaz., Madrid, Spain

Background: Giant cell arteritis (GCA) is the most frequent systemic vasculitis in older than 50 years old, with marked general state involvement or ischemic phenomena that can cause blindness to the patient's death. Its form of presentation is heterogeneous however the therapeutic approach tends to be homogeneous. In recent years, the possible existence of subtypes of the disease has been pointed out and this can have important repercussions in the prognosis and approach of the disease. Two studies have suggested that the coexistence of GCA and Polymyalgia rheumatica (PMR) identifies a subgroup of patients at low risk for developing cranial ischemic symptoms. However, this was refuted by three other studies that did not find that effect.

Objectives: To study if, excluding the articular manifestations, the GCA against the association of PMR with ACG presents a phenotype with clinical differences relevant in clinical practice.

Methods: Retrospective observational study based on data from the Database of Hospital from the Spanish National Health Service with primary or secondary diagnostic of GCA between January $1^{\text {st }}, 2005$ and December 31th, 2015. In this substudy the data demographics and comorbidities and mortality, presenting patients with GCA were collected and compared with patients with GCA and PMR.

Results: The study cohort included 29.576 patients with GCA, of whom 4,189 had PMR as an associated diagnosis. The comorbidities associated with $A C G$ and $A C G / P M R$ and the statistical significance of the differences can be seen in the table. As a relevant fact, a lower risk of mortality was observed in patients presenting GCA along with PMR (OR 0.682 IC95\% 0,581-0,801) and a lower frequency of cerebrovascular events and ischemic optic neuropathy.

Table 1. Differences between GCA associated with PMR vs ACG without PMR

\begin{tabular}{lccccc}
\hline & & \multicolumn{2}{c}{ WTIHOUT PMR } & \multicolumn{2}{c}{ WITH PMR } \\
\hline & & $\mathrm{N}$ & $\%$ & $\mathrm{~N}$ & $\%$ \\
\hline Sex $^{*}$ & Men & 9533 & $37,6 \%$ & 1474 & $35,2 \%$ \\
& Woman & 15853 & $62,4 \%$ & 2715 & $64,8 \%$ \\
Age & $\leq 74$ & 5646 & $22,2 \%$ & 997 & $23,8 \%$ \\
group $^{*}$ & & & & & \\
& $75-79$ & 5779 & $22,8 \%$ & 954 & $22,8 \%$ \\
& $80-84$ & 6789 & $26,7 \%$ & 1210 & $28,9 \%$ \\
& $\geq 85$ & 7173 & $28,3 \%$ & 1028 & $24,5 \%$ \\
DM2* $^{*}$ & & 6486 & $25,5 \%$ & 1131 & $27,0 \%$
\end{tabular}




\begin{tabular}{lccccc} 
RENAL & & 3393 & $13,4 \%$ & 576 & $13,8 \%$ \\
ICC* & 3651 & $14,4 \%$ & 501 & $12,0 \%$ \\
IHM & & 1035 & $4,1 \%$ & 156 & $3,7 \%$ \\
Cancer $^{*}$ & & 1177 & $4,6 \%$ & 131 & $3,1 \%$ \\
ECV $^{*}$ & & 1030 & $4,1 \%$ & 123 & $2,9 \%$ \\
EPOC & 736 & $2,9 \%$ & 112 & $2,7 \%$ \\
ION $^{*}$ & & 431 & $1,7 \%$ & 41 & $1 \%$ \\
CCI $^{*}$ & $\quad$ Without & 11943 & $47,0 \%$ & 2065 & $49,3 \%$ \\
& Comorbidities & & & & \\
& & 12355 & $48,7 \%$ & 1977 & $47,2 \%$ \\
& 2 Comorbidities & 1089 & $4,3 \%$ & 147 & $3,5 \%$ \\
Mortality $^{*}$ & 2 Comorbidities & 1618 & $6,4 \%$ & 177 & $4,2 \%$ \\
\hline
\end{tabular}

*Statistically significant differences $(P<0.05)$ DM2: Diabetes mellitus Type 2 PMR: Polymyalgia rheumatica ICC: Congestive heart failure IHM: Ischemic Heart Disease ECV: Cerebrovascular disease ION: ischemic optic neuropathy $\mathrm{CCI}$ : Charlson Index of Comorbidities

Conclusion: The patients with GCA with PMR represent a subtype of GCA with lower risk of stroke, ischemic optic neuropathy and mortality than patients with ACG without associated PMR.

Disclosure of Interests: : None declared

DOI: 10.1136/annrheumdis-2019-eular.3368

\section{THU0296 CORRELATIONS AMONG VASCULAR ULTRASOUND ABNORMALITIES OF THE TEMPORAL AND LARGE ARTERIES IN GIANT CELL ARTERITIS}

Michael Diiorio ${ }^{1}$, Piotr Sobieszczyk ${ }^{2}$, Julia Ford ${ }^{1}$, William Docken ${ }^{1}$, Sara Tedeschi ${ }^{1}$. ${ }^{1}$ Brigham and Women's Hospital, Division of Rheumatology, Allergy and Immunology, Boston, United States of America; ${ }^{2}$ Brigham and Women's Hospital, Division of Cardiovascular Medicine, Boston, United States of America

Background: Vascular ultrasound (VUS) is a sensitive and specific method for evaluating giant cell arteritis (GCA). Understanding patterns of temporal artery (TA) and large artery involvement may be important for aiding in diagnosis.

Objectives: To determine correlations among VUS abnormalities in patients with GCA.

Methods: We performed a retrospective study among 503 patients that underwent VUS to evaluate suspected or known GCA at an academic medical center, 2013-2017. Demographics, clinical features, VUS reports, and pathology data were extracted through electronic medical record review. Trained cardiovascular ultrasonographers imaged the right and left temporal, common carotid (CCA), subclavian (SCA), and axillary (AXA) arteries. The superficial temporal arteries (STA) and their frontal (TA-F) and parietal (TA-P) branches were abnormal if halo sign or hyperechoic wall thickening was present; the CCA, SCA and AXA were abnormal if those findings and/or stenosis or occlusion were present. Cardiovascular medicine physicians trained in VUS interpreted studies as acute arteritis, no arteritis, or hyperechoic wall thickening without acute arteritis. Among patients diagnosed with GCA by the treating physician $(n=139)$, we determined correlations between abnormal vessels using phi coefficients ( $\phi)$. We created composite variables representing each TA and its branches, and the left and right CCA, SCA, and AXA to test correlations between temporal and large arteries. Significance was determined using Fisher's exact test with Bonferroni correction.

Results: Among 139 patients, 50\% were diagnosed before VUS (median disease duration 17 months). Median age at VUS was 73 years; $75 \%$ were female and $93 \%$ White. Forty patients $(29 \%)$ had TA biopsy-proven GCA; an additional $14(10 \%)$ had biopsy-proven giant cell aortitis. Prevalence of abnormalities of TAs and large arteries were similar $(20 \%$ of right and $27 \%$ of left TAs; $20 \%$ of right and $24 \%$ of left large arteries). VUS was consistent with acute arteritis in $32 \%$, no arteritis in $53 \%$, and hyperechoic without acute arteritis in $15 \%$. Abnormalities in the STA, TA$F$, and TA-P were moderately correlated ipsilaterally $(\phi=0.46-0.62$, $p<0.0001)$ and contralaterally $(\phi=0.51-0.58, p<0.0001)$ (Table). Abnormalities in the AXA and SCA were strongly correlated with the ipsilateral and contralateral AXA and SCA $(\phi=0.64-0.82, \quad p<0.0001)$. Correlation between right and left TAs was moderate $(\phi=0.59, p<0.0001)$, while a stronger relationship was found between right and left large arteries $(\phi=$ $0.77, p<0.0001)$. Abnormalities in TAs were not correlated with large arteries ( $\phi \approx 0$ for all comparisons; not significant).

Conclusion: We observed moderate correlations of TA branches and strong correlations of large artery branches on VUS among GCA patients. Abnormalities in the TAs and large arteries were not correlated, underscoring the importance of scanning both groups of vessels with VUS.

\begin{tabular}{|c|c|c|c|}
\hline Artery & Correlated Artery & $\phi$ & $p$ \\
\hline \multirow[t]{4}{*}{$\overline{\text { R STA }}$} & R TA-F & 0.60 & $\dagger$ \\
\hline & R TA-P & 0.62 & $\dagger$ \\
\hline & L STA & 0.58 & $\dagger$ \\
\hline & L TA-F & 0.51 & $\dagger$ \\
\hline \multirow[t]{2}{*}{ R TA-F } & R TA-P & 0.58 & $\dagger$ \\
\hline & L STA & 0.48 & $\dagger$ \\
\hline R TA-P & L TA-P & 0.51 & $\dagger$ \\
\hline L STA & L TA-F & 0.55 & $\dagger$ \\
\hline L TA-F & L TA-P & 0.46 & $\dagger$ \\
\hline R CCA & L CCA & 0.66 & $\dagger$ \\
\hline \multirow[t]{3}{*}{ R AXA } & R SCA & 0.81 & $\dagger$ \\
\hline & L AXA & 0.82 & $\dagger$ \\
\hline & L SCA & 0.81 & $\dagger$ \\
\hline L AXA & L SCA & 0.69 & $\dagger$ \\
\hline \multirow[t]{2}{*}{ R SCA } & L AXA & 0.64 & $\dagger$ \\
\hline & L SCA & 0.73 & $\dagger$ \\
\hline \multirow[t]{3}{*}{$\begin{array}{l}\mathrm{R} \text { temporal } \\
\text { composite }\end{array}$} & $\begin{array}{l}\mathrm{L} \text { temporal } \\
\text { composite }\end{array}$ & 0.59 & $\dagger$ \\
\hline & $\mathrm{R}$ large composite & -0.07 & NS \\
\hline & L large composite & -0.07 & NS \\
\hline \multirow{2}{*}{$\begin{array}{l}\text { L temporal } \\
\text { composite }\end{array}$} & $\mathrm{R}$ large composite & 0.06 & NS \\
\hline & L large composite & 0.05 & NS \\
\hline $\mathrm{R}$ large composite & L large composite & 0.77 & $\dagger$ \\
\hline
\end{tabular}

Temporal composite: abnormal superficial TA, TA-frontal branch, and/or TA-parietal branch. Large composite: abnormal common carotid, subclavian, and/or axillary artery. NS: not significant

$\dagger p<0.0001$

Disclosure of Interests: None declared

DOI: 10.1136/annrheumdis-2019-eular.2902

\section{THU0297 STEROID TREATMENT MAY IMPROVE ARTERIAL STIFFNESS IN PATIENTSWITH POLYMYALGIA RHEUMATICA AND GIANT CELL ARTERITIS: A PROSPECTIVE COHORT STUDY}

Amir Emamifar ${ }^{1,2,3}$, Torkell Ellingsen ${ }^{4}$, Søren Hess ${ }^{5,6}$, Per Syrak Hansen ${ }^{2}$, Inger Marie Jensen Hansen ${ }^{3}$, Peter Thye-Rønn ${ }^{1,2}$. ${ }^{1}$ University of Southern Denmark, Clinical Research, Odense, Denmark; ${ }^{2}$ Svendborg Hospital, Diagnostic Center Svendborg, Denmark; ${ }^{3}$ Svendborg Hospital, Rheumatology, Svendborg, Denmark; ${ }^{4}$ Odense University Hospital, Rheumatology, odense, Denmark; ${ }^{5}$ Hospital of Southwest Jutland, Radiology and Nuclear Medicine, Esbjerg, Denmark;

${ }^{6}$ University of Southern Denmark, Regional Health Research, Odense, Denmark

Background: Polymyalgia rheumatica (PMR)/Giant cell arteritis (GCA), common inflammatory diseases, are associated with increased risk of aortic stiffness, possibly due to an inflammatory process. ${ }^{1,2}$

Objectives: To evaluate the effect of steroid treatment on aortic stiffness in patients with PMR/GCA.

Methods: This is an ongoing 1-year prospective cohort study. 37 consecutive patients with newly diagnosed PMR/GCA were included. Aortic pulse wave velocity (PWV) and aortic augmentation index normalized to heart rate of 75 beats per minute (Alx@75) were measured at baseline and subsequently at $1^{\text {st }}$ and $4^{\text {th }}$ months of treatment initiation with oral prednisolone.

Results: Of 37 patients, 3 pts. were excluded from the study because of lack of interest or a change in the initial diagnosis. Of all included pts. $61.8 \%$ were female and mean age was 71 (69-74) years. At diagnosis 24 pts. presented with pure PMR symptoms, 2 pts. with pure cranial GCA, 8 pts.with concurrent PMR and GCA. The mean of erythrocyte sedimentation rate (ESR) and C-reactive protein (CRP) at baseline were $62.3 \pm 22.9$ and $46.4 \pm 43.7$, respectively. Alx@75 was significantly

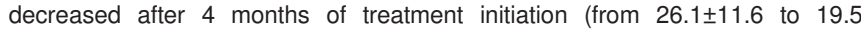
$\pm 11.5, p=0.016$ ). Though aortic PWV was decreased after 4 months of treatment initiation (from $12.3 \pm 2.4$ to $11.6 \pm 2.4$ ), the results was not statistically significant $(p=0.070)$. We did not find any significant changes at $1^{\text {st }}$ month, nor in aortic PWV neither in Alx@75.

Conclusion: Steroid treatment may improve arterial stiffness in PMR/GCA patients due to suppression of the inflammatory process. However this is a time consuming effect and may not be seen as early as the first month.

\section{REFERENCES:}

[1] Emamifar A, et al. Polymyalgia rheumatica and giant cell arteritis-three challenges-consequences of the vasculitis process, osteoporosis, and 